\title{
Depositions and characterization of sol-gel processed Al-doped ZnO (AZO) as transparent conducting oxide (TCO) for solar cell application
}

\author{
Afrina Sharmin $^{1,2} \cdot$ Samia Tabassum ${ }^{1} \cdot$ M. S. Bashar ${ }^{1} \cdot$ Zahid Hasan Mahmood $^{2}$
}

Received: 10 January 2019 / Accepted: 20 April 2019 / Published online: 8 May 2019

(c) The Author(s) 2019

\begin{abstract}
Al-doped $\mathrm{ZnO}$ (AZO) thin films are deposited on glass substrate by sol-gel spin coating using zinc acetate dihydrate as a precursor with different molar concentrations varying from 0.35 to $0.75 \mathrm{~mol} / \mathrm{L}$. To investigate the structural, electrical, optical and morphological properties of AZO films, XRD, four-point probes, HE measurement, UV-Vis spectrometry and SEM with EDX are used. Thickness of the thin film is measured by a surface profilometer. The structural characteristics show a hexagonal wurtzite structure with a (002)-preferred orientation. Optical study reveals that transmittance is very high (up to 90\%) within the visible region and optical band gap, $E_{\mathrm{g}}$ varies from 3.25 to $3.29 \mathrm{eV}$ with $\mathrm{Zn}$ concentration. The carrier concentration increases and resistivity decreases with the increase in $\mathrm{Zn}$ concentration. Thin films fabricated with $0.75 \mathrm{~mol} / \mathrm{L}$ of $\mathrm{Zn}$ concentration exhibit the best electrical property. SEM study shows non-uniform surface of the films where EDX confirms the formation of AZO. The results revealed by this study prompt a high interest to use AZO as transparent conductive oxide for advanced applications such as displays, solar cells and optoelectronic devices.
\end{abstract}

Keywords Spin coating $\cdot$ Band gap $\cdot$ Solar cell $\cdot$ Transparent conductive oxide (TCO) $\cdot$ Photovoltaic

\section{Introduction}

$\mathrm{ZnO}$ has achieved a significant interest of the research community over the last decade because of its widespread and potential application. This material is being used in biomedical science, ceramic industry, cosmetics, concrete manufacturing and even in food products. $\mathrm{ZnO}$ is prominently used as transparent electrode in solar cells, touch screens, LCDs, plasma display panels (PDPs) and OLEDs which are growing in demand [1,2]. Impurity-doped $\mathrm{ZnO}[2,3]$ is an amazing candidate for the transparent conducting oxide (TCO) which has replaced ITO and FTO with its unique electrical and optical features. TCO works as a window layer of a photovoltaic cell that has greater than $80 \%$ transmittance of incident light. Other versatile application of $\mathrm{ZnO}$ includes quantum-dot LED [4], lithium-ion battery anodes [5], piezoelectric devices such as surface acoustic wave (SAW) and

Afrina Sharmin

sharmin_afrina@bcsir.gov.bd

1 Institute of Fuel Research and Development (IFRD), BCSIR, Dhanmondi, Dhaka 1205, Bangladesh

2 Department of Electrical and Electronic Engineering, University of Dhaka, Dhaka 1000, Bangladesh piezoelectric sensors, anti-reflection coatings, field-effect transistors, voltage-dependent resistor (VDR), chemical and biological sensors and gas sensors in electronic noses [6].

$\mathrm{n}$-Type $\mathrm{ZnO}$ possesses a large exciton binding energy of $60 \mathrm{meV}$ with excellent chemical and thermal stability [7] and has a wide gap $\left(E_{\mathrm{g}}=3.37 \mathrm{eV}\right)$. So it can be doped or codoped to improve its optical properties. When $\mathrm{Al}$ is doped into $\mathrm{ZnO}$, it elevates the free charge carriers and broadens the optical band gap [8]. The elements of Group 3 (e.g., Al, $\mathrm{Ga}$ ) are used as doping material to increase the number of carriers which decreases the resistivity. Impurity-doped $\mathrm{ZnO}$ attracts much attention as it revealed both low resistivity and high transmittance which are mostly expected for the window layer of a solar cell. In addition, AZO consists of non-toxic and earth abundant element and has low growth temperature [9], which make it suitable for low-cost largescale coating. Thus, AZO has become the material of choice of solar cell technology though ITO has been studied over 50 years and possesses most beneficial properties as TCO.

Thin films of AZO can be prepared by various techniques such as spray pyrolysis [10], chemical vapor deposition (CVD) [11], sputtering [12], laser ablation [13], plasma-enhanced CVD (PECVD) [14], single-source CVD (SSCVD) [15], metal-organic CVD (MOCVD) [16], pulsed 
laser deposition (PLD) [16], molecular beam epitaxy (MBE) [16], thermal oxidation of $\mathrm{Zn}$ or $\mathrm{ZnS}$ [17, 18] and atomic layer deposition (ALD) [19]. Yang et al. [20] reported highquality transparent and conducting room-temperature deposition of AZO films by magnetron sputtering and studied the effect of thermal annealing in different atmospheres. Tabassum et al. [21] reported a comparative study of sputtered and sol-gel processed AZO films with their oxidation kinetics. Most of these deposition processes such as physical or chemical vapor deposition require high temperature yielding high-quality films which are not always suitable for lift-off fabrication technology. The process complexity needs to be overcome and manufacturing cost is low. The method such as sol-gel [22, 23] process is not only inexpensive, but also a simple and smooth process for synthesizing large-area thin films of any material which is done at room temperature. It allows excellent compositional control, a high degree of homogeneity on the molecular level and a low crystallization temperature. Highly oriented and transparent $\mathrm{ZnO}$ thin films have been reported by Khan et al. [24] using the sol-gel technique. Tonny et al. [25] investigated the optical, electrical and structural properties of AZO film with varying film thicknesses deposited by sol-gel spin coating method.

Effect of Al doping on optical and structural properties of $\mathrm{Al}-\mathrm{ZnO}$ is studied by Lee et al. [26] using vacuum evaporation method and by Tabassum et al. [27] using sol-gel method. The resistivity increased for 3-4 wt $\% \mathrm{Al}$ concentration. Another study [28] investigated the electrical stability of AZO film for different annealing temperatures and time durations. It concludes that annealing duration does not have any significant effect and high-temperature annealed film shows better stability. Several studies also have been reported on AZO thin film with varying thickness [25, 29] and annealing atmosphere [29-33]. Controlling of crystallite size, shape and crystallinity along with these various parameters still needs to be inquired. Material stoichiometry (metallic precursor with compositional uniformity) is one of the vital factors to obtain high-quality transparent AZO films. A very few study is reported on the effect of $\mathrm{Zn}$ concentration on the properties of AZO till date. Taking these under consideration, a simple and low-cost technique such as sol-gel spin coating method is employed here to fabricate AZO thin films for a systematic investigation. The purpose of this work is to fabricate a high-quality transparent AZO thin film and to reconnoiter the area of enhancing the properties of the thin film as TCO. A higher knowledge of the interrelation between different properties of a thin film is essential in order to achieve better understanding of film stoichiometry. The influence of film thickness on different properties of AZO has been reported to find out an optimum thickness for AZO film. Secondly, the influence of molar concentration of $\mathrm{Zn}$ precursor is also studied for the investigation of electro-optical quality of AZO film as a transparent conductive electrode. Moreover, applying low-cost sol-gel method to obtain AZO thin film as an alternative of expensive ITO or FTO is the outstanding aspect of this research.

\section{Materials and methods}

\section{Specimen preparation}

Zinc acetate dihydrate $\left(\mathrm{Zn}\left(\mathrm{CH}_{3} \mathrm{COO}\right)_{2} \cdot 2 \mathrm{H}_{2} \mathrm{O}\right)$ and Aluminum nitrate nonahydrate $\left(\mathrm{Al}\left(\mathrm{NO}_{3}\right)_{3} \cdot 9 \mathrm{H}_{2} \mathrm{O}\right)$ were used as the precursor of $\mathrm{ZnO}$ and dopant precursor, respectively to prepare the sol-gel [27]. Precursor concentration was varied from 0.35 to $0.75 \mathrm{~mol} / \mathrm{L}$. At first, Zinc acetate dihydrate and Aluminum nitrate nonahydrate were dissolved in 2-methoxyethanol (solvent). A few drops of monoethanolamine (MEA) were added. MEA to Zinc acetate molar ratio was set to 1 . Here, MEA acts as a complexing agent. The solution was stirred at $60^{\circ} \mathrm{C}$ for $1 \mathrm{~h}$ by a magnetic stirrer to get a clean and homogeneous solution. The precursor solution was left for 15-20 h for aging. The substrates of soda lime glass (SLG) were cleaned by methanol, ethanol, again methanol for $10 \mathrm{~min}$ each and with DI water in an ultrasonic bath for $15 \mathrm{~min}$ [34]. A spin coater (SPS SPIN 150 ) is employed for deposition with $3000 \mathrm{rpm}$ for $30 \mathrm{~s}$ at room temperature. Synthesized films were preheated with an oven (Binder, ED 53) at $300{ }^{\circ} \mathrm{C}$ for 5 min after each coating. It was dried and cooled naturally. This procedure was repeated 5, 10, 15 and 20 times to increase the thickness. So samples of four different thicknesses were prepared for each concentration with the 5th, 10th, 15 th and 20th layers. The films were subsequently heated up to $500{ }^{\circ} \mathrm{C}$ for $1 \mathrm{~h}$ in a closed $\mathrm{N}_{2}$ atmosphere in order to obtain crystallized AZO.

\section{Characterization}

The thickness of the film was measured with a surface profilometer (Dektak, Bruker). X-ray diffractometer (GBC, $\varepsilon M M A)$ was used to study the structural characteristics of the sol-gel derived Al-doped $\mathrm{ZnO}$ thin film. The system with $\mathrm{Cu}-\mathrm{K} \alpha$ radiation and wavelength of $1.5406 \AA$ was operated at $35 \mathrm{kV}$ and $28 \mathrm{~mA}$. A UV-visible spectrophotometer (UH4150, Hitachi) was used to study optical transmittance in the visible wavelength. The electrical properties of Aldoped $\mathrm{ZnO}$ thin films were measured using a Hall effect measurement system (HT55T3, Ecopia) employing the van der Pauw technique. A scanning electron microscope (SEM, Zeiss, EVO 18) was used to study surface topography, and EDX (EDAX, AMETEK) was used to obtain quantitative compositional information. 


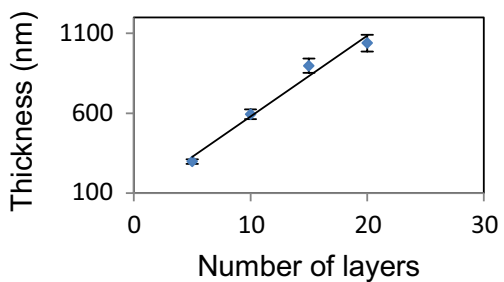

Fig. 1 Thickness variance with the number of layers

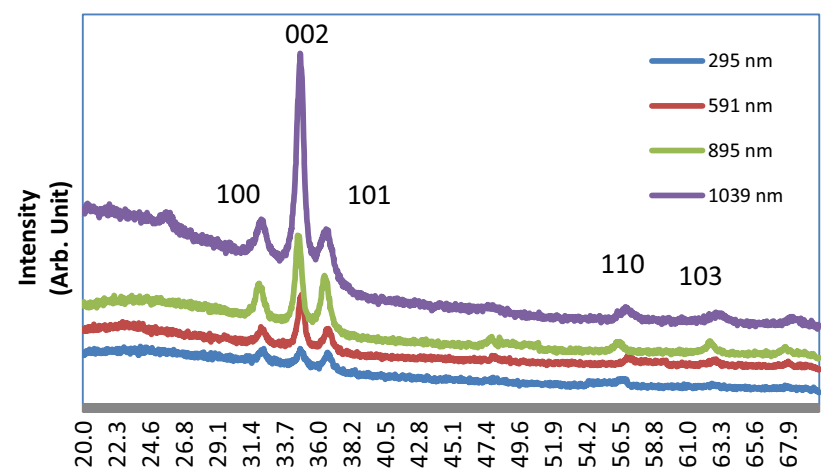

2 theta (degrees)

Fig. 2 X-ray diffraction spectra of AZO film with $\mathrm{Zn}$ concentration of $0.75 \mathrm{~mol} / \mathrm{L}$

\section{Results and discussion}

The thickness with the number of coated layers of sol-gel processed AZO thin film is shown in Fig. 1 with error bars. It increases linearly with the increase in coating numbers ranging from 295 to $1039 \mathrm{~nm}$.

\section{Structural properties}

The X-ray diffraction pattern for the AZO thin film annealed at $500{ }^{\circ} \mathrm{C}$ is shown in Fig. 2. Below $500{ }^{\circ} \mathrm{C}$, AZO does not show any strong peak. In this study, AZO crystallites have a hexagonal wurtzite structure (ICDD-00051-0037). The spectra shows a dominant peak at $34.60^{\circ}$ reflecting the preferential orientation along the crystallographic axis (002). Other peaks at $31.80^{\circ}$ and $36.30^{\circ}$ with less intensity are observed at axes (100) and (101), respectively. All sample shows c-plane preferred orientation. It can be observed that the peak intensity and sharpness increase with film thickness. Peak sharpness suggests increasing crystallite size with increasing thickness [25, 35].

To compare the structure features of AZO film, the full width at half maximum (FWHM) of XRD (002) peak, $d$-spacing $(\Delta)$, crystallite size $(D)$, dislocation density $(\delta)$ and strain $(\varepsilon)$ are listed in Table 1 . The crystallite size, $D$, is measured from Scherrer's formula [24]

$D=\frac{k \lambda}{\beta \operatorname{Cos} \theta}$

where $D$ is the crystallite size, $\lambda$ is the wavelength of XRD, $\beta$ is the value of full width at half maximum (FWHM) in radians and $\theta$ is the angle of diffraction.

The dislocation density, $\delta$, is the number of dislocations in a unit volume of a crystalline material which is calculated from [24]

$\delta=\frac{1}{D^{2}}$

Regular pattern of a crystal is disrupted by dislocation [36]. Strain, $\varepsilon$, of the thin film is measured by the equation [24]

$\varepsilon=\frac{\beta \operatorname{Cos} \theta}{4}$

The smaller FWHM $(\beta)$ and larger crystallite size $(D)$ indicate better crystallization of AZO thin film. From Table 1, it is observed that crystallite size $(D)$ increases with increasing thickness and varies from 9.25 to $9.81 \mathrm{~nm}$. Crystallite size $(D)$ mainly depends on annealing temperature and annealing atmosphere [20]. No drastic change in crystallite size is observed here as this study is carried out with a constant annealing temperature. In addition, the effect of defects is not considered for calculating crystallite size. Dislocation density, $\delta$, decreases with increasing thickness, which indicates lower lattice imperfections and lower strain of the AZO film. It can be observed from Table 1 that an increase in thickness of the films reduces the crystal defects.
Table 1 Microstructural parameters of AZO thin film with $\mathrm{Zn}$ concentration $0.75 \mathrm{~mol} / \mathrm{L}$

\begin{tabular}{llllll}
\hline No. of layers & $d$-spacing $\Delta(\AA)$ & FWHM $\beta\left(^{\circ}\right)$ & $\begin{array}{l}\text { Crystallite } \\
\text { size } D(\mathrm{~nm})\end{array}$ & $\begin{array}{l}\text { Dislocation den- } \\
\text { sity, } \delta\left(\text { Lines } / \mathrm{m}^{2}\right)\end{array}$ & Strain, $\varepsilon 10^{-3}$ \\
\hline 5 th & 2.69 & 0.8912 & 9.25 & 1.16 & 3.89 \\
10 th & 2.70 & 0.8792 & 9.55 & 1.09 & 3.63 \\
15 th & 2.71 & 0.8660 & 9.67 & 1.06 & 3.60 \\
20 th & 2.69 & 0.7940 & 9.81 & 1.01 & 3.30 \\
\hline
\end{tabular}




\section{Electric properties: effect of $\mathrm{Zn}$ concentration}

Figures 3, 4 and 5 depict the electrical properties of AZO thin films as a function of film thickness with different $\mathrm{Zn}$ concentrations of $0.35,0.50$ and $0.75 \mathrm{~m} / \mathrm{L}$, respectively. From Fig. 3, it is observed that resistivity $(\rho)$ decreases gradually whereas sheet concentration $(n)$ increases with a film thickness. These phenomena can be attributed due to an increase in sheet concentration $(n)$ as a result of the formation of free electrons and due to an increase in mobility $(\mu)$. Sheet carrier concentration/sheet concentration is the number of carriers per unit square. And bulk carrier concentration/bulk concentration is the number of carriers per unit volume. If the thickness of the film is known

$n_{\mathrm{s}}=n_{\mathrm{b}} * h$

where $n_{\mathrm{s}}=$ sheet carrier concentration, $n_{\mathrm{b}}=$ bulk carrier concentration and $h=$ thickness of the films. Yang et al. [20] reported room-temperature deposition of AZO in 2010 which explained the dependence of electric property on carrier concentration, contribution from $\mathrm{Al}^{3+}$ on substitutional sites of $\mathrm{Zn}^{2+}$ ions, oxygen vacancies and $\mathrm{Zn}$ interstitial
Fig. 3 Variance of electric properties with thickness AZO thin films with $\mathrm{Zn}$ concentration of $0.35 \mathrm{~mol} / \mathrm{L}$
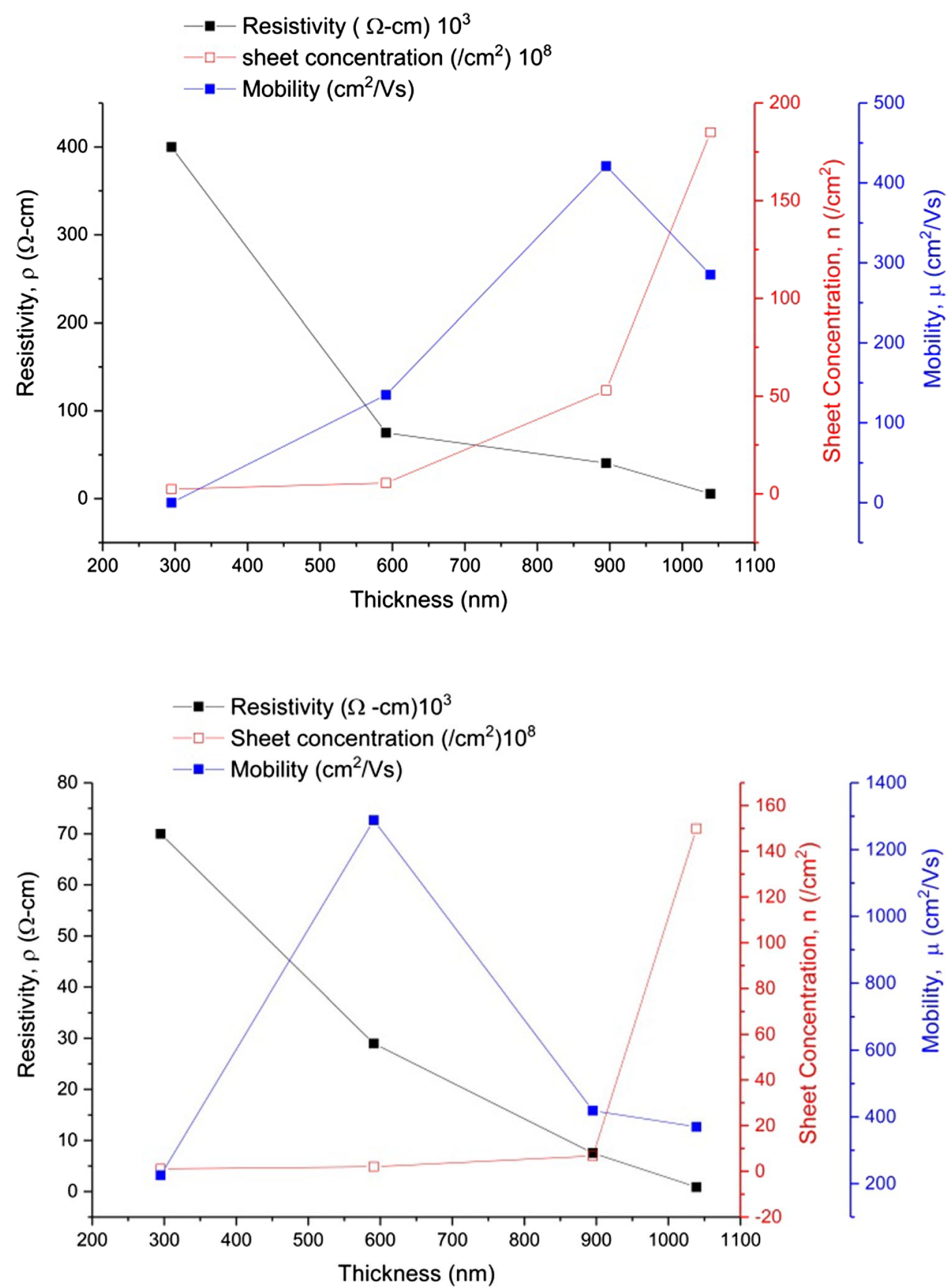
Fig. 5 Variance of electric properties with thickness of AZO thin films with $\mathrm{Zn}$ concentration of $0.75 \mathrm{~mol} / \mathrm{L}$

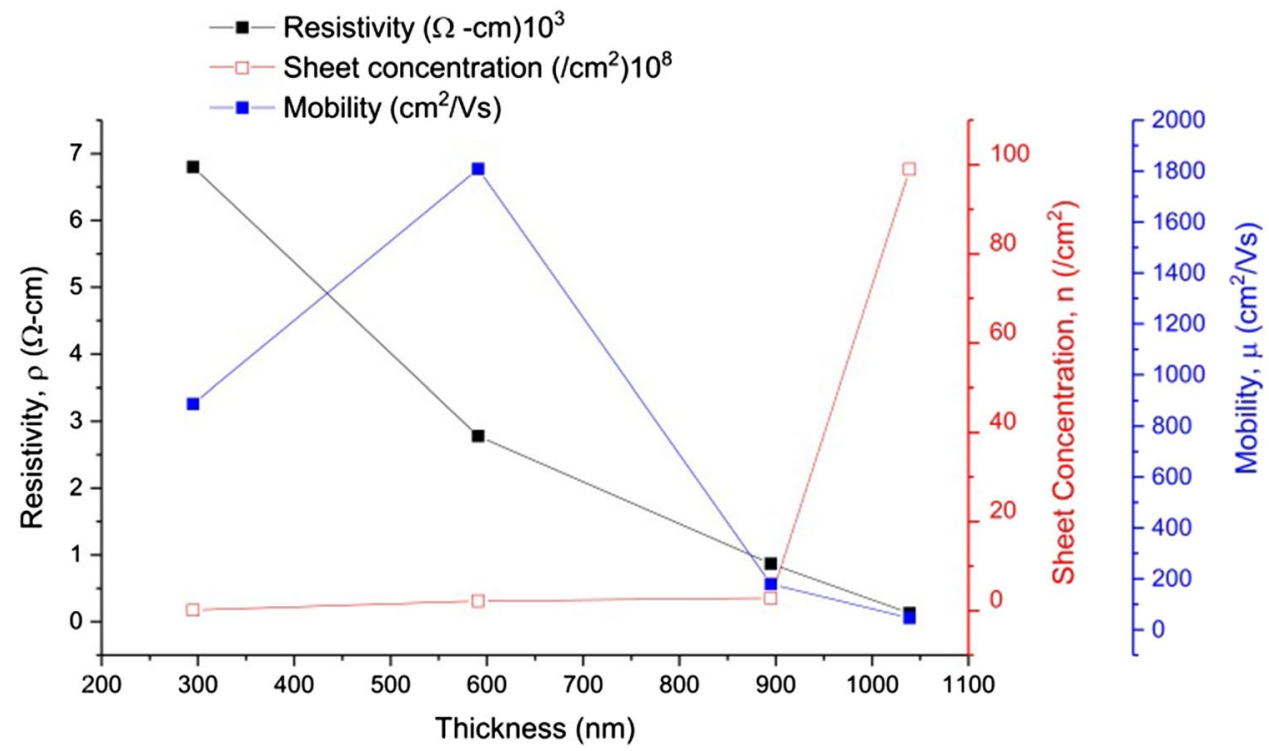

atoms. Annealing atmosphere has an important effect on carrier concentration [37]. For this study, annealing atmosphere is same for all samples and $2 \mathrm{wt} \% \mathrm{Al}$ doping is chosen as it shows the lowest resistivity and optimum electrical stability compared to 1, 3 and $4 \mathrm{wt} \% \mathrm{Al}$ [27]. It is reported that excess $\mathrm{Al}$ doping creates non-conducting $\mathrm{Al}_{2} \mathrm{O}_{3}$. It behaves like a carrier trap; consequently, there is an increase in resistivity [38]. So it can be concluded that the decrease in resistivity $(\rho)$ is attributed to the change in $\mathrm{Zn}$ concentration which enhances the creation of free electron as shown in Figs. 3, 4 and 5 .

It can be clearly speculated from Figs. 3, 4 and 5 that the range of resistivity $(\rho)$ decreases (i.e., conductivity increases) gradually with $\mathrm{Zn}$ concentration from 0.35 to $0.75 \mathrm{~mol} / \mathrm{L}$. And it is comparatively lowest for the $\mathrm{Zn}$ concentration of $0.75 \mathrm{~mol} / \mathrm{L}$. The lowest resistivity among 12 samples is obtained as $1.3 \times 10^{2} \Omega \mathrm{cm}$ for 20 th layer (1039 $\mathrm{nm}$ ) although it can be improved by changing the annealing atmosphere [37] and ensuring controlled doping concentration [27].

However, the mobility $(\mu)$ increases gradually with film thickness up to 15 th layer and then starts to decrease (Fig. 3). Guillen et al. [37] reported that mobility is mainly influenced by layer thickness. Mobility $(\mu)$ increases up to a certain value with thickness until there is a sufficient carrier concentration. When carrier concentration reaches to a certain level, it opposes the mobility of the carrier. So there is a decrease in mobility $(\mu)$. Figures 4 and 5 show similar characteristics with increasing thickness. In Fig. 4, mobility $(\mu)$ shows increasing tendency with film thickness up to 10th layer $(591 \mathrm{~nm})$ and then starts to decrease toward 20th layer $(1039 \mathrm{~nm})$. The highest mobility is shown as $1.81 \times 10^{3} \mathrm{~cm}^{2} / V_{\mathrm{s}}$ for 10 th layer $(591 \mathrm{~nm})$ for $\mathrm{Zn}$ concentration of $0.75 \mathrm{~mol} / \mathrm{L}$ in Fig. 5.
The electric property is measured at room temperature by a Hall effect measurement system. Phenomena such as adsorption of oxygen and water molecule by AZO film at the annealing atmosphere can lower the carrier concentration and thus might affect the conductivity of the sample [39]. Annealing (post heat treatment) with argon (Ar) or pure hydrogen $\left(\mathrm{H}_{2}\right)$ flow shows better and stable electric properties [27]. The number of $\mathrm{O}_{2}$ vacancies directly affects the electrical property of AZO thin film. As annealing in $\mathrm{H}_{2}$ causes $\mathrm{O}_{2}$ annihilation, $\mathrm{O}_{2}$ vacancies are formed in the film. This vacancy, which acts as a carrier, consequently decreases the resistivity $(\rho)$. The report shows that resistivity of AZO film decreases significantly for pure $\mathrm{H}_{2}$ than for $\mathrm{Ar}+5 \% \mathrm{H}_{2}$ annealing atmosphere [28].

\section{Optical properties: effect of $\mathrm{Zn}$ concentration}

The optical transmittance spectra for different layers (5th, 10th, 15th and 20th layers) of the AZO thin film grown on SLG are shown in Figs. 6, 7 and 8 for the concentration of $0.35,0.50$ and $0.75 \mathrm{~mol} / \mathrm{L}$, respectively. A sharp ultraviolet cutoff is observed approximately at $380 \mathrm{~nm}$. It can be observed from Fig. 6 that average value of transmittance $(\% T)$ is $90-92 \%$ for five layers $(295 \mathrm{~nm})$. And transmission decreases gradually with increasing thickness and lowest for 20 layers. A comparison of Figs. 6, 7 and 8 depicts that average transmittance $(\% T)$ decreases gradually with increasing $\mathrm{Zn}$ concentration which is fairly reflected by a band gap calculation. The absorption coefficient is calculated by

$(\alpha h v)^{2}=A\left(h v-E_{\mathrm{g}}\right)^{1 / 2}$ 
Fig. 6 Optical transparency of AZO films with $\mathrm{Zn}$ concentration of $0.35 \mathrm{~mol} / \mathrm{L}$
Fig. 7 Optical transparency of AZO films with $\mathrm{Zn}$ concentration of $0.50 \mathrm{~mol} / \mathrm{L}$
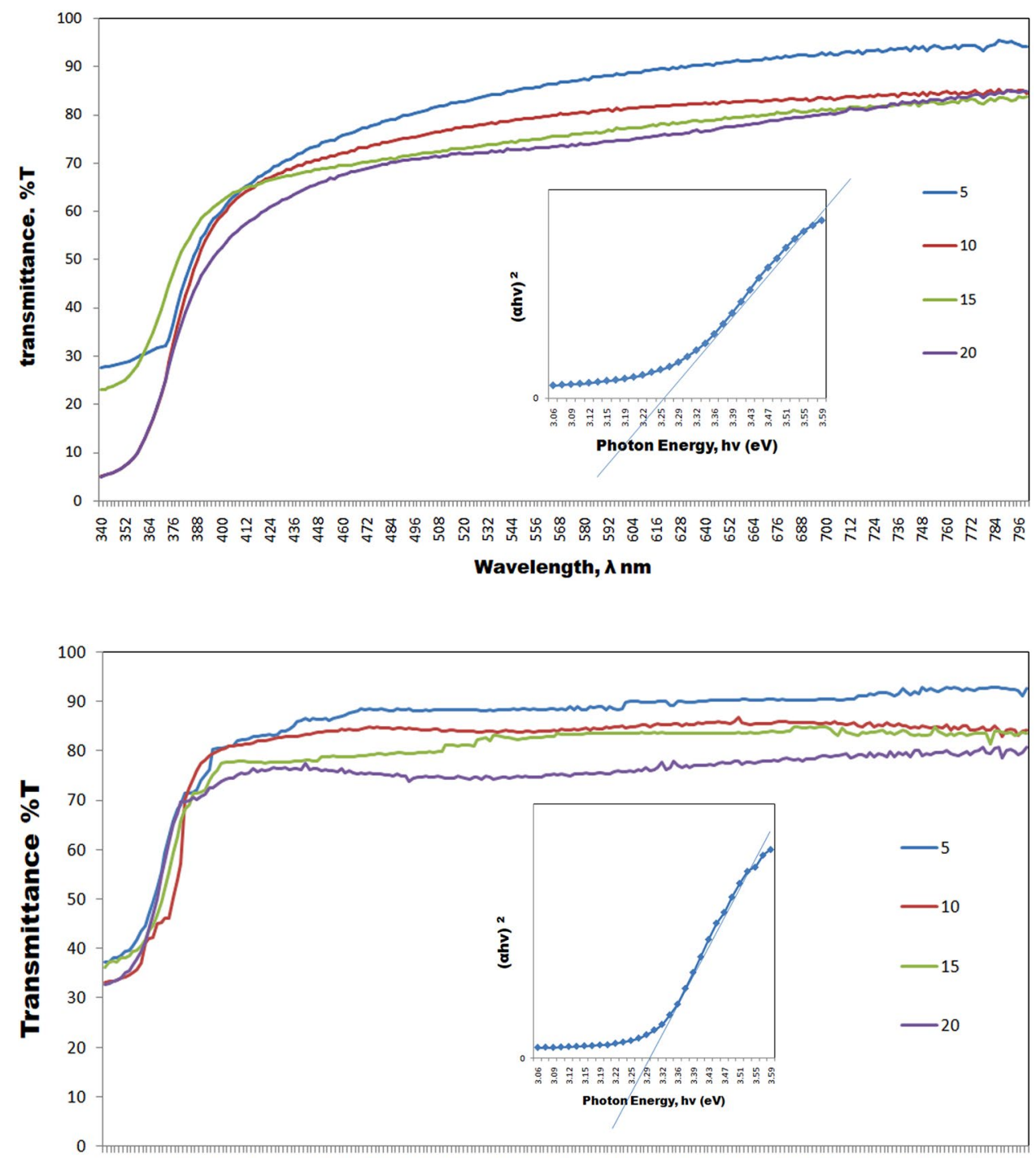

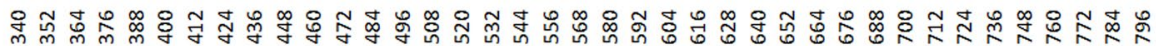

Wavelength $\lambda \mathbf{~ n m}$

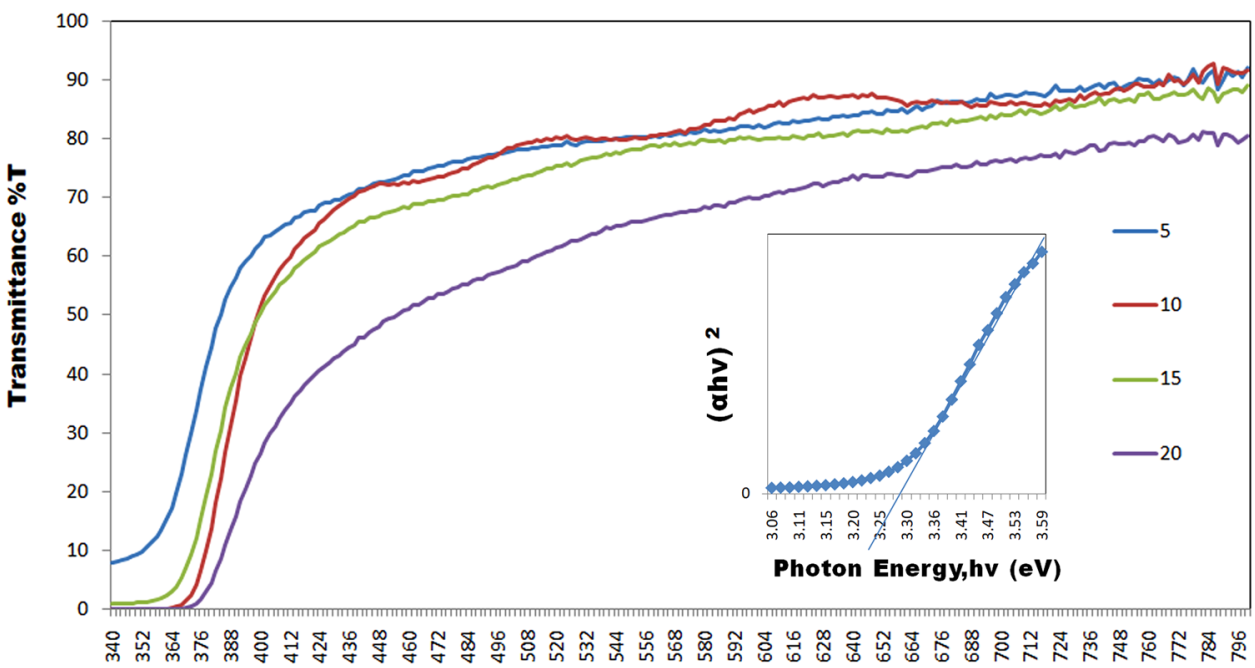

Wavelength, $\Lambda \mathrm{nm}$ 
Table 2 Optical dielectric constant $\left(\varepsilon_{\mathrm{o}}\right)$ and optical high-frequency dielectric constant $\left(\varepsilon_{\infty}\right)$ values for AZO film

\begin{tabular}{llll}
\hline $\begin{array}{l}\text { Zn concentra- } \\
\text { tion }(\mathrm{mol} / \mathrm{L})\end{array}$ & $\begin{array}{l}\text { Band gap } \\
\text { energy } E_{\mathrm{g}} \\
(\mathrm{eV})\end{array}$ & $\begin{array}{l}\text { High-frequency elec- } \\
\text { trostatic constant }\end{array}$ & $\begin{array}{l}\text { Static dielec- } \\
\text { tric constant }\end{array}$ \\
\hline 0.35 & 3.25 & 8.51 & 5.76 \\
0.50 & 3.28 & 8.42 & 5.73 \\
0.75 & 3.29 & 8.39 & 5.72 \\
\hline
\end{tabular}

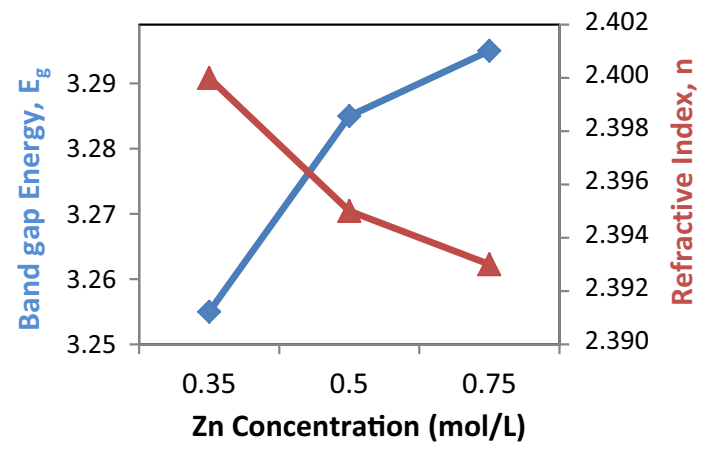

Fig. 9 Variation of band gap energy, $E_{\mathrm{g}}(\mathrm{eV})$, and refractive index, $n$, with $\mathrm{Zn}$ concentration

Here, $E_{\mathrm{g}}$ is the band gap, $\nu$ is the frequency of incident radiation, $h$ is the Plank's constant and $A$ is a constant. The Tauc plot is drawn for each concentration shown inset of Figs. 6, 7 and 8. The optical band gap increases from 3.25 to $3.29 \mathrm{eV}$ (listed in Table 2) with increasing $\mathrm{Zn}$ concentration. Band gap widening is also related to carrier concentration increase. Moreover, it directly affects the transmittance of a film. Burstein-Moss theory explains the phenomena of increase in transmittance with the widening of the band gap [40, 41]. The relation between band gap energy, $E_{\mathrm{g}}$, and refractive index, $n$, with molar concentration is shown in Fig. 9.

The band gap $\left(E_{\mathrm{g}}\right)$, refractive index $(n)$ and dielectric constant $(\varepsilon)$ of semiconducting materials are essential for designing heterostructure laser in optoelectronic devices as well as solar cell applications [42]. The efficiency of organic solar cells still lags behind inorganic solar cells due to their low dielectric constant.

The refractive index $(n)$ or index of refraction of a material is a dimensionless number that describes how fast light propagates through that medium. In a solar cell, the refractive index is more suppressed by adding $\mathrm{i}-\mathrm{ZnO}$ (antireflection coating) between absorber and window layer [43]. Refractive index is defined as

$n=c / v$

where $c$ is the speed of light in vacuum and $v$ is the phase velocity of light in the medium. It is directly related to band gap by Moss relation as

$E_{\mathrm{g}} n^{4}=k$

Here, $k$ is a constant with a value of $108 \mathrm{eV}$. The dielectric constant is a quantity measuring the ability of a substance to store electrical energy in an electric field. It is the ratio of the permittivity of a substance to the permittivity of free space. Control on the medium dielectric constant can reduce the $V_{\text {oc }}$ loss toward device efficiency improvement in solar cells. The high-frequency dielectric constant $\left(\varepsilon_{\infty}\right)$ is measured from the relation

$\varepsilon_{\infty}=n^{2}$

The static dielectric constant $\left(\varepsilon_{\mathrm{o}}\right)$ of the film is calculated as

$\varepsilon_{\mathrm{o}}=18.52-3.08 E_{\mathrm{g}}$

The value of optical dielectric constant $\left(\varepsilon_{\mathrm{o}}\right)$ and optical high-frequency dielectric constant $\left(\varepsilon_{\infty}\right)$ of AZO film is given in Table 2.

\section{Morphological properties}

SEM images are given in Fig. 10a-d showing the surface topography of the films with the 5th, 10th, 15th and 20th layers. The film has covered the substrate surface but seems rough most of the places. Some places look wrinkled and voids are observed. The voids are the preferable diffusion path for oxygen and water molecule to enter into the film. The phenomena increase the resistance of the AZO film [21]. The unsymmetrical AZO rod is shown in Fig. 10d. Similar type of pattern is also observed by Khan et al. [22] and Znaidi et al. [44]. Figure 11 shows the EDX graph of the relative abundance of the material versus X-ray energy. EDX measurement confirms the formation of AZO with 57.7\% of $\mathrm{O}_{2}, 41.9 \%$ of $\mathrm{Zn}$ and $0.4 \%$ of Al. Uniform composition is important to enhance the performance of AZO films [43]. The achieved composition of AZO film is in good agreement with the values reported by Lee et al. [26]. 


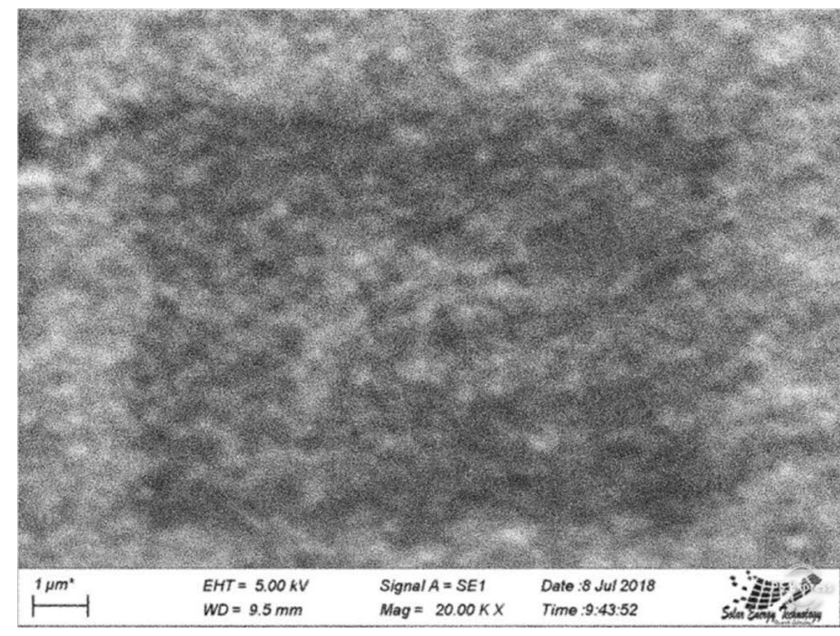

(a)

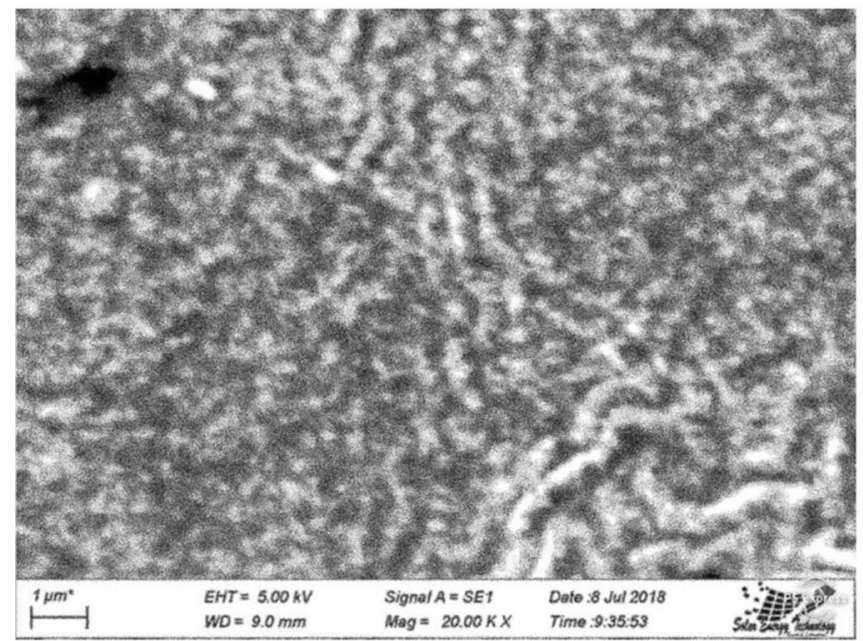

(c)

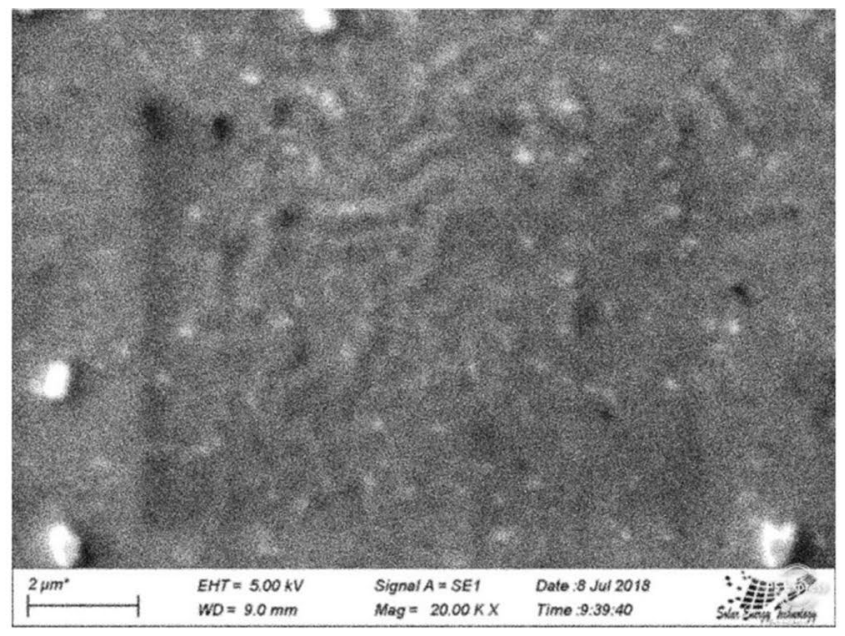

(b)

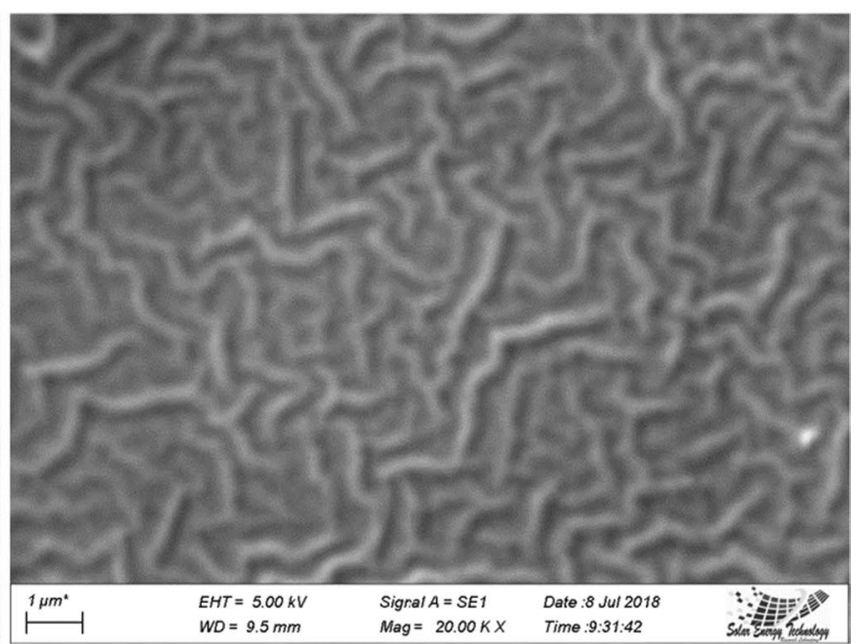

(d)

Fig. 10 SEM images of AZO film with thickness of a 295 nm, b $591 \mathrm{~nm}, \mathbf{c} 895 \mathrm{~nm}$ and d $1039 \mathrm{~nm}$

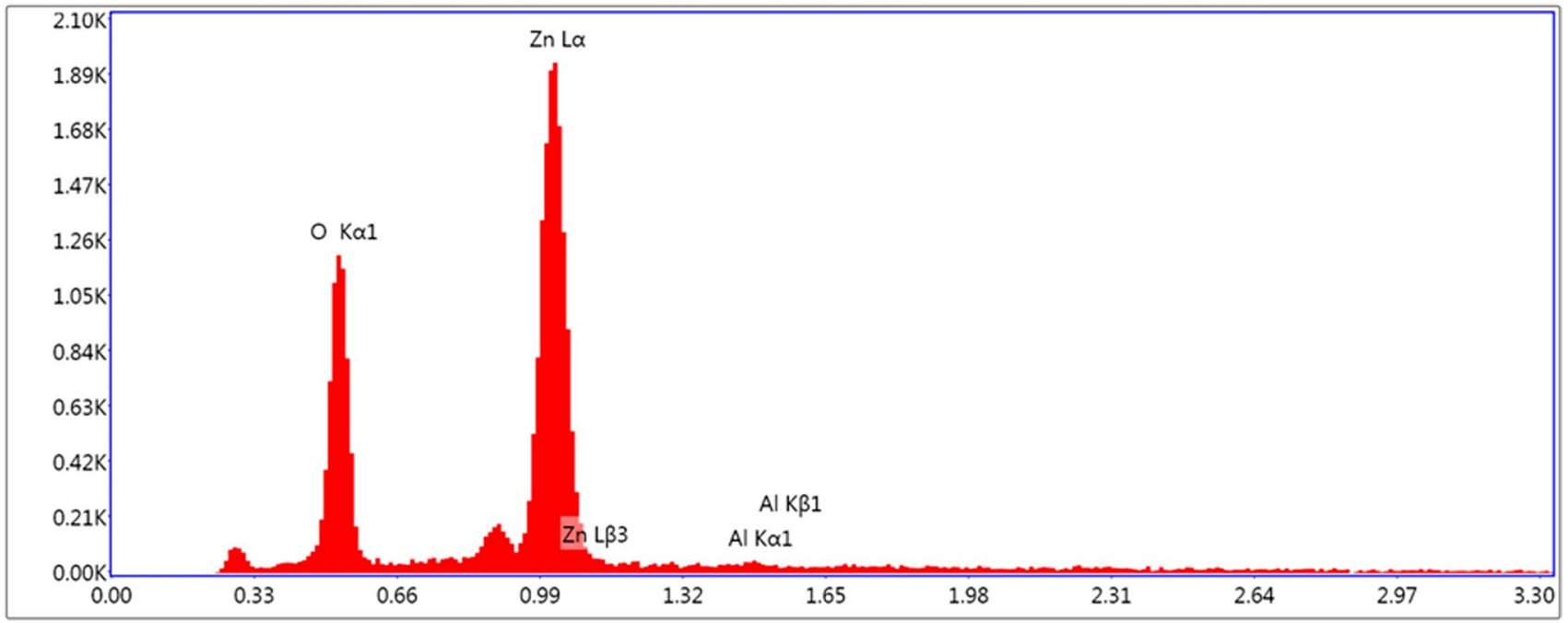

Lsec: 30.00 Cnts $0.000 \mathrm{keV}$ Det: Octane Prime Det

Fig. 11 EDX spectrum for AZO film 


\section{Conclusion}

$\mathrm{ZnO}$ nanoparticle is being used in a self-cleaning coating on a metal panel [45] and even in anti-corrosion nanocoating of carbon steel [46] in recent time. For its exquisite electric and optical properties, AZO has become the most promising candidate of transparent electrode for both photovoltaic [47] and plasmonic solar cell [48]. In this study, highly transparent AZO thin film is successfully deposited on SLG by a novel sol-gel spin coating technique at room temperature. Different properties of AZO film are methodically inquired. The XRD analysis revealed that AZO film has a c-axis (002)-oriented hexagonal crystal structure. The grain size $(D)$ of the film is observed to increase and strain $(\varepsilon)$ decreases with increasing film thickness. The effect of $\mathrm{Zn}$ concentrations on optical and electrical properties of Al-doped $\mathrm{ZnO}$ thin film has been studied. The transmittance ( $\%$ T) of AZO films was greater than $90 \%$ in the visible region which gradually decreases with film thickness as well as with $\mathrm{Zn}$ concentration. The electrical property of AZO is mostly affected by carrier concentration, mobility and doping concentration. This study was performed for a particular doping concentration. So a change in $\mathrm{Zn}$ concentration has preceded the creation of more free electron, which implies that the increase in $\mathrm{Zn}$ concentration is efficacious to boost the electric property of AZO. Film with $1039 \mathrm{~nm}$ thickness exhibits lowest resistivity $(\rho)$ and film with $595 \mathrm{~nm}$ thickness shows the highest mobility $(\mu)$ for $0.75 \mathrm{~mol} / \mathrm{L} \mathrm{Zn}$ concentration. The band energy $\left(E_{\mathrm{g}}\right)$ is broadened $(3.25-3.29 \mathrm{eV})$ and refractive index (n) decreased as the $\mathrm{Zn}$ concentration is increased. Considering the facts revealed by electrical and optical properties, it can be concluded that $\mathrm{Zn}$ concentration of $0.75 \mathrm{~mol} / \mathrm{L}$ is the most suitable for AZO film as transparent conduction oxide for photovoltaic application. Moreover, EDX study provides both qualitative and quantitative analyses of AZO thin films. 1039-nm-thick film shows fewer voids with better coverage than others.

Acknowledgements The authors gratefully acknowledge Institute of Fuel Research and Development (IFRD) of BCSIR, Dhaka, Bangladesh, for the logistic support of this research work.

Open Access This article is distributed under the terms of the Creative Commons Attribution 4.0 International License (http://creativeco mmons.org/licenses/by/4.0/), which permits unrestricted use, distribution, and reproduction in any medium, provided you give appropriate credit to the original author(s) and the source, provide a link to the Creative Commons license, and indicate if changes were made.

\section{References}

1. Plain, D.C., Yeom, H.Y., Yaglioglu, B.: Flexible flat. In: Crawford, G.P. (ed.) Panel Displays, vol. 94. Wiley, Singapore (2005)
2. Lewis, B.G., Plain, D.C.: Applications and processing of transparent conducting oxides. MRS Bull. 25(8), 22 (2000)

3. Park, S.M., Ikegami, T., Ebihara, K.: Investigation of transparent conductive oxide Al-doped $\mathrm{ZnO}$ films produced by pulsed laser deposition. Jpn. J. Appl. Phys. 44, 8027 (2005)

4. Wang, Y., Zhao, W., Zou, M., Chen, Y., Yang, L., Xu, L., Wu, H., Cao, A.: MOF-derived $\mathrm{ZnO}$ nanoparticles covered by $\mathrm{N}$-doped carbon layers and hybridized on carbon nanotubes for lithium-ion battery anodes. ACS Appl. Matter. Interfaces 9(43), 37813-37822 (2017)

5. Sun, Y., Wang, W., Zhang, H., Su, Q., Wei, J., Liu, P., Chen, S., Zhang, S.: High-performance quantum dot light-emitting diodes based on Al-doped $\mathrm{ZnO}$ nanoparticles electron transport layer. ACS Appl. Mater. Interfaces 10(22), 18902-18909 (2018)

6. Lupan, O., et al.: Nanostructured zinc oxide films synthesized by successive chemical solution deposition for gas sensor applications. Mater. Res. Bull. 44, 63-69 (2009)

7. Klingshirn, C.: ZnO: from basics towards applications. Phys. Status Solidi B 244(9), 3027-3073 (2007)

8. Zi-qiang, X., Hong, D., Yan, L., Hang, C.: Al-doping defects on structure, electrical and optical properties of c-axis-orientated ZnO: Al thin films. J. Optoelectron. Laser 17(3), 257-260 (2006)

9. Fang, G., Li, D., Yao, B.L.: Fabrication and vacuum annealing of transparent conductive AZO thin films prepared by DC magnetron sputtering. Vacuum 68(4), 363-372 (2002)

10. Paraguay, F.D., Estrada, W.L., Acosta, D.R.N., Andrade, E., Mikiyoshida, M.: Growth, structure and optical characterization of high quality $\mathrm{ZnO}$ thin films obtained by spray pyrolysis. Thin Solid Films 350, 192-202 (1999)

11. Moustaghfir, A., Tomasella, E., Amor, S.B., Jcquet, M., Cellier, J., Sauvage, T.: Comparison of the structural and optical properties of zinc oxide thin films deposited by d.c. and r.f. sputtering and spray pyrolysis. Surf. Coat. Technol. 200, 293-296 (2005)

12. Haga, K., Kamidaira, M., Kashiwaba, Y., Sekiguchi, T., Watanabe, $\mathrm{H}$.: $\mathrm{ZnO}$ thin films prepared by remote plasma-enhanced CVD method. J. Cryst. Growth 214, 77-80 (2000)

13. Narasimhan, K.L., Pai, S.P., Palka, V.R., Pinto, R.: High quality zinc oxide films by pulsed laser ablation. Thin Solid Films 295, 104-106 (1997)

14. Barankin, M.D., Gonzalez II, E., Ladwig, A.M., Hicks, R.F.: Plasma-enhanced chemical vapor deposition of zinc oxide at atmospheric pressure and low temperature. Solar Energy Mater. Sol. Cells 91, 924-930 (2007)

15. Dai, L.P., Deng, H., Zang, J.D., Mao, F.Y., Chen, J.J., Wei, M.: The effect of annealing temperature on the properties of $\mathrm{ZnO}$ films with preferential nonpolar plane orientation by SSCVD. J. Mater. Sci. 43, 312-315 (2008)

16. Triboulet, R., Perrière, J.: Epitaxial growth of $\mathrm{ZnO}$ films. Prog. Cryst. Growth Charact. Mater. 47, 65-138 (2003)

17. Sekar, A., Kim, S.H., Umar, A., Hahn, Y.B.: Catalyst-free synthesis of $\mathrm{ZnO}$ nano wires on $\mathrm{Si}$ by oxidation of $\mathrm{Zn}$ powders. J. Cryst. Growth 277, 471-478 (2005)

18. Ibanga, E.J., le Luyer, C., Mugnier, J.: Zinc oxide waveguide produced by thermal oxidation of chemical bath deposited zinc sulphide thin films. Mater. Chem. Phys. 80, 490-495 (2003)

19. Yen, C.Y., et al.: Influence of annealing temperature on the structural, optical and mechanical properties of ALD-derived ZnO thin films. Appl. Surf. Sci. 257, 7900-7905 (2011)

20. Yang, W., et al.: Room temperature deposition of Al-doped $\mathrm{ZnO}$ films on quartz substrates by radio-frequency magnetron sputtering and effects of thermal annealing. Thin Solid Films 519(1), 31-36 (2010)

21. Tabassum, S., Yamasue, E., Okumura, H., Ishihara, K.N.: Sol-gel and rf sputtered AZO thin films: analysis of oxidation 
kinetics in harsh environment. J. Mater. Sci. Mater. Electron. 25(11), 4883-4888 (2014)

22. Bao, D., Gu, H., Kuang, A.: Sol-gel-derived c-axis oriented $\mathrm{ZnO}$ thin films. Thin Solid Films 312, 37-39 (1998)

23. Sakti, N., Gupta, P.S.: Structural and optical properties of solgel prepared ZnO thin film. Appl. Phys. Res. 2(1), 19-28 (2010)

24. Khan, Z.R., Khan, M.S., Zulfequar, M., Khan, M.S.: Optical and structural properties of $\mathrm{ZnO}$ thin films fabricated by sol-gel method. Mater. Sci. Appl. 2, 340-345 (2011)

25. Tonny, K.N., Rafique, R., Sharmin, A., Bashar, M.S., Mahmood, Z.H.: Electrical, optical and structural properties of transparent conducting $\mathrm{Al}$ doped $\mathrm{ZnO}$ (AZO) deposited by sol-gel spin coating. AIP Adv. 8, 065307 (2018)

26. Lee, G.Z.: Optical and structural properties of Al-ZnO nanocomposites. J. Nanosci. Nanotechnol. 14, 3661-3666 (2014)

27. Tabassum, S., Yamasue, E., Okumura, H., Ishihara, K.N.: Damp heat stability of AZO transparent electrode and influence of thin metal film for enhancing the stability. J. Mater. Sci. Mater. Electron. 25, 3203-3208 (2014)

28. Tabassum, S., Yamasue, E., Okumura, H., Ishihara, K.N.: Electrical stability of Al-doped $\mathrm{ZnO}$ transparent electrode prepared by sol-gel method. Appl. Sci. Surf. 377, 355-360 (2016)

29. Ohyama, M., Kozuka, H., Yoko, T.: Sol-gel preparation of transparent and conductive aluminum-doped zinc oxide films with highly preferential crystal orientation. J. Am. Ceram. Soc. 81, 1622-1632 (1998)

30. Schuler, T., Aegerter, M.A.: Optical, electrical and structural properties of sol gel ZnO: Al coatings. Thin Solid Films 351, 125-131 (1999)

31. Valle, G.G., Hammer, P., Pulcinelli, S.H., Santilli, C.V.: Transparent and conductive $\mathrm{ZnO}$ : Al thin films prepared by sol-gel dip-coating. J. Eur. Ceram. Soc. 24(6), 1009-1013 (2004)

32. Tahar, R.B.H.: Structural and electrical properties of aluminumdoped zinc oxide films prepared by sol-gel process. J. Eur. Ceram. Soc. 25(14), 3301-3306 (2005)

33. Lin, K.M., Tsai, P.: Growth mechanism and characterization of $\mathrm{ZnO}$ : Al multi-layered thin films by sol-gel technique. Thin Solid Films 515(24), 8601-8604 (2007)

34. Cavas, M.: Investigation morphological, electrical, and optical properties of $\mathrm{Mn}$-doped $\mathrm{ZnO}$ thin film by sol-gel spin-coating method. J. Theor. Appl. Phys. 11, 325-331 (2017)

35. Rafique, R., Tonny, K.N., Sharmin, A., Mahmood, Z.H.: Study on the effect of varying film thickness on the transparent conductive nature of aluminum doped zinc oxide deposited by dip coating. Mater. Focus 7(5), 7070-7713 (2018)

36. Thool, G.S., Singh, A.K., Singh, R.S., Gupta, A., Susan, M.A.B.H.: Facile synthesis of flat crystal $\mathrm{ZnO}$ thin films by solution growth method: a micro-structural investigation. J. Saudi Chem. Soc. 18(5), 712-721 (2014)

37. Guillen, C., Herrero, J.: Optical, electrical and structural characteristics of $\mathrm{Al}: \mathrm{ZnO}$ thin films with various thickness deposited by DC sputtering at room temperature and annealed in air or vacuum. Vacuum 84, 914-929 (2010)

38. Hu, J., Gordon, R.G.: Textured aluminum-doped zinc oxide thin films from atmospheric pressure chemical-vapor deposition. J. Appl. Phys. 71, 880-890 (1992)

39. Chen, T.L., et al.: Highly stable Al-doped $\mathrm{ZnO}$ transparent conductors using an oxidized ultrathin metal capping layer at its percolation thickness. Appl. Phys. Lett. 99, 093302 (2011)

40. Bennett, B.R., Soref, R.A., Del Alamo, J.A.: Carrier-induced change in refractive index of InP, GaAs and InGaAsP. IEEE J. Quantum Electron. 26, 113-122 (1990)

41. Djouadi, D., Chelouche, A., Aksas, A.: Amplification of the UV emission of $\mathrm{ZnO}$ : Al thin films prepared by sol-gel method. J. Mater. Environ. Sci. 3(3), 585-590 (2012)

42. Ondo-Ndong, R., et al.: Capacitive properties of zinc oxide thin films by radiofrequency magnetron sputtering. J. Theor. Appl. Phys. 12(4), 309-317 (2018)

43. Jheng, B.T., Liu, P.T., Wang, M.C., Wu, M.C.: Effects of ZnOnanostructure antireflection coatings on sulfurization-free $\mathrm{Cu}_{2} \mathrm{ZnSnS}_{4}$ absorber deposited by single-step co-sputtering process. Appl. Phys. Lett. 103(5), 29041-4 (2013)

44. Znaidi, L., Soler-Illia, G.J.A.A., Benyahia, S., Sanchez, C., Kanaev, A.V.: Oriented $\mathrm{ZnO}$ thin films synthesis by sol-gel process for laser application. Thin Solid Films 428(1-2), 257-262 (2003)

45. Stieberova, B., et al.: Application of $\mathrm{ZnO}$ nanoparticles in a self-cleaning coating on a metal panel: an assessment of environmental benefits. ACS Sustain. Chem. Eng. 5(3), 2493-2500 (2017)

46. Hasnidawani, J.N., et al.: $\mathrm{ZnO}$ nanoparticles for anti-corrosion nanocoating of carbon steel. Mater. Sci. Forum. 894, 76-80 (2017)

47. Pisoni, S., et al.: Impact of interlayer application on band bending for improved electron extraction for efficient flexible perovskite mini-modules. Nano Energy 49, 300-307 (2018)

48. Delerue, C.: Minimum line width of surface plasmon resonance in doped ZnO nanocrystals. Nano Lett. 1712, 7599-7605 (2017)

Publisher's Note Springer Nature remains neutral with regard to jurisdictional claims in published maps and institutional affiliations. 